\title{
Avaliação escolar: ressignificação do instrumento prova presencial tradicional com a utilização de uma ferramenta digital para testes rápidos
}

\author{
Adriano Barbosa Lima (MPNTDE | UniCarioca) \\ Heloisa Elaine da Silva Carvalho Lopes (MPNTDE | UniCarioca) \\ Marcelo Queres de Oliveira (MPNTDE | UniCarioca) \\ Victor Gonçalves Freitas (NUCAP | MPNTDE | UniCarioca) \\ Alessandro Jatobá(NUCAP | MPNTDE | FIOCRUZ) \\ Verônica Elói (MPNTDE | UniCarioca) \\ Bianca Martins (NUCAP | MPNTDE | UniCarioca | PUC-Rio)
}

\section{Resumo}

O objeto deste estudo é a ressignificação da prática de avaliação com o instrumento prova presencial tradicional, utilizando a ferramenta Plickers. O estudo baseou-se em uma pesquisa bibliográfica e documental. Foi feita uma análise detalhada da prática a ser ressignificada a partir da observação da experiência de uso da mesma, além de uma análise de oportunidades de ressignificação a partir de uma visão de Design e produção de sentidos com identificação de sujeitos praticantes e análise do relato da experiência de um professor com a utilização da ferramenta proposta. Conclui-se com a pesquisa que a mudança da avaliação de resultados para uma avaliação de processo é possível com a utilização da ferramenta Plickers.

Palavras-chave: Avaliação Escolar; Ferramenta Digital; Testes Rápidos; Design e Produção de Sentido.

\begin{abstract}
The object of this study is the re-signification of the evaluation practice with the traditional face-test instrument, using the Plickers tool. The study was based on a bibliographical and documentary research. A detailed analysis of the practice to be redefined from the observation of the experience of using it was made. In addition to an analysis of opportunities of re-signifcation from a vision of Design and production of senses with identification of practicing subjects and analysis of the report of the experience of a teacher with the use of the proposed tool. It is concluded with the research that the change of the evaluation of results for a process evaluation is possible with the use of the Plickers tool.
\end{abstract}

Keywords: School Evaluation; Digital Tool; Quick Tests; Design and Production of Meaning.

\section{Introdução}

O presente artigo é resultado do relato da experiência de um professor de uma instituição pública de ensino da cidade do Rio de Janeiro acerca de sua percepção sobre a prova escolar e tem como objetivo ressignificar a prática da avaliação somativa ou classificatória com o instrumento prova presencial tradicional para realizar uma avaliação formativa e diagnóstica utilizando a ferramenta Plickers. Além disso, o trabalho também visa refletir a respeito do papel que o modelo tradicional de prova exerce em sala de aula no contexto atual.

A avaliação tem um papel significativo no processo educativo e por isso precisa ser repensada. Na maioria das escolas, aplica-se uma prova ou teste após determinado período de exposição do conteúdo, para avaliação da aprendizagem, tornando-a uma ferramenta classificatória e excludente muito mais centrada na promoção do que na formação.

Isso ocorre porque

[...] aplicam estas provas controlando o ambiente: não procedem a explicações, não realizam leituras, não permitem qualquer movimentação. Posteriormente, corrigem as provas atribuindo notas e devolvem as provas e "orientam" os alunos com rendimento insuficiente para "estudarem mais". Na verdade, ao assim procederem, os professores restringem sua ação à realização de uma avaliação unicamente classificatória [...].(MORAES, 2008, p. 51). 
A avaliação deve assumir um caráter formativo e não apenas classificatório, uma vez que a avaliação não se resume apenas a uma prova. Esta serve como um instrumento de diagnóstico e dá ao professor a possibilidade de refletir sua ação docente e ao mesmo tempo propicia ao aluno condições para que perceba seu processo de aprendizagem e possa autoavaliar-se e autorregular-se. Neste cenário, o professor será

[...] capaz de comprovar os conhecimentos realmente assimilados pelos alunos. [...] E ao analisar os resultados do rendimento escolar dos alunos, obtém informações sobre o desenvolvimento do seu próprio trabalho. O professor pode perguntar-se: "Meus objetivos estão suficientemente claros? Os conteúdos estão acessíveis, significativos e bem dosados? [...] Estou conseguindo comunicar-me adequadamente com todos os alunos? Estou dando a necessária atenção aos alunos com mais dificuldades? Ou estou dando preferência só aos bem-sucedidos, aos mais dóceis e obedientes?" (LIBÂNEO, 1994, p.202).

De acordo com Luciano e Moraes (2013), quando submetido a uma prova tradicional, geralmente o aluno sente uma série de expectativas frente ao seu desempenho, ou seja, ele é tomado pela ansiedade e/ou pelo medo, pois depende de uma nota para saber se está fadado ao fracasso ou ao sucesso. Entretanto, na maioria das vezes este momento não revela seu verdadeiro conhecimento, uma vez que este tipo de prova tradicional é apenas uma "análise" quantitativa de um período de estudos e não um momento qualitativo de todo um processo ensino-aprendizagem, já que dependendo da metodologia do professor, não há um devido retorno desta prova para os alunos.

Segundo Schleicher(2015), a promoção da aprendizagem eficaz dos alunos, com a utilização das tecnologias de informação e comunicação (TIC) aliadas às potencialidades das Web 2.0 tools e das tecnologias móveis, é salientada e recomendada pela Organização para a Cooperação e Desenvolvimento Econômico - OCDE.

Para auxiliar nesse processo, existem várias ferramentas na Internet, tais como Socrative, WBT-Quis Manager, Vizir, Gradepen, Kahoot, Plickers, etc. Escolhemos analisar a ferramenta Plickers por ser uma ferramenta gratuita e fácil de se utilizar.

O aplicativo Plickers favorece uma avaliação dinâmica, descontraída, lúdica, que permite mensurar, instantaneamente, o nível de aprendizado, promovendo, se necessário, uma revisão direcionada ao tema que apresentou baixo rendimento, dando à avaliação um caráter formativo em vez de classificatório. Além de dar um feedback momentâneo ao aluno e professor, permite um registro permanente de cada avaliação.

Diante do exposto, levantamos a seguinte questão: A substituição do modelo tradicional de prova presencial escrita aplicada num determinado período (mensal, bimestral, etc.) pela contínua utilização da ferramenta Plickers ao longo desse mesmo período propicia ao professor parâmetros para uma avaliação formativa em vez de de classificatória?

\section{Metodologia}

O estudo baseou-se em uma pesquisa bibliográfica e documental, destacando alguns autores que versam sobre a prova presencial tradicional na esfera escolar. Sendo assim, explicitamos que em nossa pesquisa utilizamos os autores Perrenoud (1999), Luckesi (2005), Libaneo (1994) e Moraes (2008), procurando dessa forma nos inteirar sobre o instrumento prova tradicional presencial tão utilizado na escola pelos professores.

Foi feita uma análise detalhada da prática a ser ressignificada a partir da observação da experiência de seu uso: adequação entre forma e funções; significado e discurso: mobilidade e imobilidade; Ecologia das Mídias: linguagem, tecnologia e fruição e análise sintática e semântica do instrumento avaliativo, com base em Cardoso(2012), Horn(1998) e Santaela (2004).

Há também uma análise de oportunidades de ressignificação a partir de uma visão de Design e produção de sentidos com identificação de sujeitos praticantes (personas): as preferências de leitura através do mapa da empatia que foi elaborado com bases nas respostas dadas nas entrevistas aplicadas a oito professores de uma escola pública do Rio de Janeiro, aos quais pretende-se propor o uso do Plickers para avaliar. No questionário, havia perguntas sobre o que pensam, sentem, veem, ouvem, falam, suas dores e seus ganhos.

Foi feita a coleta e análise do relato da experiência de um professor (um dos autores deste artigo) com a utilização da ferramenta Plickers em sala de aula com seus alunos em uma instituição pública de ensino da cidade do Rio de Janeiro 
e sua percepção sobre prova escolar.

\section{Fundamentação teórica}

\section{Avaliação}

Segundo Luckesi (2002), a forma como se avalia é crucial para a concretização do projeto educacional. É ela que sinaliza aos alunos o que o professor e a escola valorizam.

Avaliar vem do latim a + valere, que significa atribuir valor e mérito ao objeto em estudo. Portanto, avaliar é atribuir um juízo de valor sobre a propriedade de um processo para a aferição da qualidade do seu resultado, porém, a compreensão do processo de avaliação do processo ensino/aprendizagem tem sido pautada pela lógica da mensuração, isto é, associa-se o ato de avaliar ao de "medir" os conhecimentos adquiridos pelos alunos.(Kraemer, 2005, p.4)

Portanto, quando utilizamos a avaliação somente para mensurar valores, praticamos uma avaliação classificatória. Para aferir a qualidade do processo ensino/aprendizagem, faz-se necessário uma avaliação formativa.

\section{Tipos de avaliação}

A avaliação, segundo Luckesi (2002), apresenta-se em três modalidades: Diagnóstica, Formativa e Somativa ou Classificatória.

A avaliação diagnóstica pretende averiguar a posição do aluno face a novas aprendizagens que lhe vão ser propostas e a aprendizagens anteriores que servem de base àquelas, no sentido de obviar as dificuldades futuras e, em certos casos, de resolver situações presentes.

Avaliação formativa é realizada com o propósito de informar o professor e o aluno sobre o resultado da aprendizagem durante o desenvolvimento das atividades escolares. Localiza a deficiência na organização do ensino-aprendizagem, de modo a possibilitar sua reformulação e assegurar o alcance dos objetivos.

A avaliação somativa tem como função classificar os alunos ao final da unidade, semestre ou ano letivo, segundo níveis de aproveitamento apresentados. O objetivo da avaliação somativa é classificar o aluno para determinar se ele será aprovado ou reprovado e está vinculada à noção de medir.

\section{Análise detalhada da prática a ser ressignificada a partir da observação da experiência de seu uso}

O artefato analisado foi um modelo de prova presencial tradicional impresso em papel A4, constituído por um cabeçalho com informações gerais (instituição, nome, turma, período, além de um espaço para nota) e questões objetivas e dissertativas sobre o conteúdo ensinado durante um curso livre de Formação Inicial Continuada de Jogos Digitais 2D. A prova foi aplicada a dez alunos com idade superior a quinze anos de idade de uma instituição de ensino pública do Rio de Janeiro.

\section{Adequação entre forma e funções}

Segundo Cardoso (2012), as formas dos artefatos não possuem um significado fixo, mas antes são expressivas de um processo de significação - ou seja, a troca entre aquilo que está embutido em sua materialidade e aquilo que pode ser depreendido delas por nossa experiência.[...] Por outro lado, formas e artefatos são passíveis de adaptação pelo uso e sujeitos a mudanças de percepção pelo juízo. [...]

O autor define artefato como um objeto feito pela incidência da ação humana. Neste caso, a prova é um objeto feito pelo professor. 
A prova tradicional pode ter significados diferentes para cada instituição de ensino, para cada professor, para cada aluno e, apesar de ter sofrido transformações quanto a sua forma (oral, manuscrita, mimeografada, impressa e virtual), mantém a mesma função de mensurar o aprendizado do aluno por meio de uma nota, classificando-o quanto ao que "aprendeu" em um dado período. A forma de avaliar não evoluiu, assim como muitas práticas e artefatos utilizados na Educação de maneira geral.

\section{Significado e discurso: mobilidade e imobilidade}

Para Cardoso (2012), o fator "discurso" refere-se ao modo como o ponto de vista de cada um encontra sua tradução para outros. Sendo assim, cabe um reflexão:

para os pais “[...] as lições e as provas são valores seguros, ou seja, é a garantia de saber se o filho está ou não aprendendo". Para a escola, a prova representa uma forma de manter a ordem, o respeito, a disciplina e a autoridade, de obrigar os alunos a estudarem, como também, é uma alternativa de assegurar que informações necessárias estão sendo apropriadas e demonstradas pelos educandos. Para os alunos a prova é, visivelmente, a maneira de ver como está sua condição de promoção ou reprovação, bem como, de identificar suas facilidades e dificuldades de aprendizagem.

Para os professores, a prova impõe respeito e autoridade e possibilita a documentação das aprendizagens e desempenhos. (LUCIANO, MORAES, 2013, p.281 apud Perrenoud, 1999, p.147).

A avaliação presencial tradicional geralmente não tem mobilidade, pois precisa ser realizada num espaço físico determinado, supervisionado por um professor ou funcionário para garantir que os alunos não consultem materiais ou colegas.

\section{Ecologia das mídias: linguagem, tecnologia e fruição}

De acordo com Coelho (2003), podemos entender como Ecologia da Mídia o estudo da comunicação humana no contexto social, em que as mídias alteram comportamentos, significados e resultados cognitivos. É composta pelo sistema simbólico (linguagem), condição de fruição (recepção) e tecnologia, em que a alteração de qualquer um deles altera o sentido da mensagem.

Quanto à linguagem, o instrumento analisado valeu-se de uma linguagem formal e escrita. A prova escrita pode conter ruídos de legibilidade e literacia para o aluno que, durante sua realização, não pode esclarecer dúvidas com o colega ou professor.

No caso desta prova, foram utilizadas ilustrações em apenas duas questões. As outras questões poderiam ser ilustradas para facilitar o entendimento do aluno, para dar ênfase, para exaltar detalhes e garantir, assim, o significado e a precisão do enunciado de cada questão.

Quanto à condição de fruição, o professor estimula um tempo para que os alunos respondam às questões da prova, que é realizada individualmente e sem consulta a materiais e que geralmente acontece num momento de expectativas e tensão por parte do aluno, o qual, na maioria das vezes, sente medo e ansiedade na hora de uma avaliação, o que pode interferir em suas interpretações e raciocínio.

A tecnologia empregada neste caso foi a impressão do instrumento prova em folhas de papel com questões que deverão ser respondidas com caneta ou lápis pelo aluno.

\section{Análise sintática da linguagem visual}

Horn (1998) propõe uma subdivisão da linguagem visual em dois níveis: Primitivo - palavras, formas e imagens; Propriedade - cor, peso, textura, tamanho, orientação, localização (no espaço bi e tridimensional), movimento, espessura e iluminação. A combinação desses dois níveis da morfologia dos elementos visuais é o começo para a sintaxe da linguagem visual. $\mathrm{O}$ arranjo sintático dos elementos na mensagem nos encoraja a unir os elementos verbais e visuais criando uma nova interpretação e produzindo um sentido. 
A seguir, na figura 1, a análise sintática da prova aplicada pelo professor antes de utilizar a ferramenta Plickers:

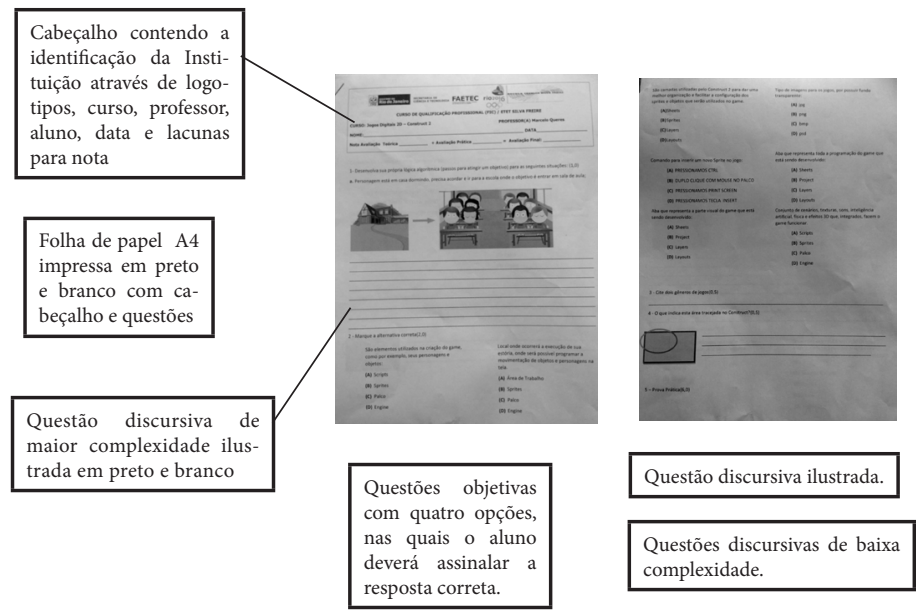

Figura 1 - Análise Sintática do instrumento prova Escolar utilizado pelo professor relator (autoria própria)

\section{Fusão semântica}

Horn (1998) denomina o processo de significação como fusão semântica. Para o autor, a fusão semântica acontece quando trazemos para as mensagens visuais nossos pensamentos e experiências com aqueles diferentes elementos que as compõem.

Os três níveis da linguagem visual - primitivo, propriedade e fusão semântica - comunicam melhor se integrados, ao invés de separados.

Para os autores deste artigo, o instrumento prova presencial tradicional possui a seguinte semântica:

Um documento formal impresso que segue o modelo tradicional de prova, exigido na maioria das escolas e aplicado em diversas disciplinas ou cursos. Contém cabeçalho (com identificação), questões objetivas, dissertativas ou práticas, escolhidas pelo professor que visam mensurar o que o aluno aprendeu num determinando período, mas, na realidade, serve somente para classificar o aluno com uma nota para merecer ou não uma aprovação.

\section{Análise de oportunidades de ressignificação a partir de uma visão de design e produção de sentidos}

\section{Identificação de sujeitos praticantes (personas): mapa da empatia e preferências de letra}

Vianna ( 2012) define Personas como "personagens ficcionais", criados a partir da análise de comportamentos observados entre pessoas com perfis extremos. Elas servem para ilustrar e representar as motivações, desejos, expectativas e necessidades do público.

Escolhemos os seguintes sujeitos praticantes em nossa pesquisa: Professores e alunos do Ensino Médio e Profissionalizante. 


\section{Mapa da empatia}

Para conhecer melhor esse público, utilizamos o Mapa de Empatia, uma ferramenta visual, para descrever o perfil de uma pessoa ou de um grupo de pessoas, normalmente construído quando é necessário documentar ou montar uma hipótese de perfil de cliente. O Mapa de Empatia pode ser feito em uma lousa, em um flip-chart ou em uma simples folha sulfite. Normalmente preenchemos um Mapa de Empatia com notas autoadesivas, do tipo post-it, mas as anotações podem ser feitas diretamente nos quadrantes.

No centro, fica a descrição geral do público-alvo a ser trabalhado, contemplando gênero, perfil demográfico e socioeconômico, entre outras características que ajudem a defini-lo de maneira mais ampla. Os outros campos informam sobre o cotidiano desta pessoa (e/ou organização), ajudando a explicitar o que ela pensa, sente, vê, escuta, fala e faz, quais são suas principais dores, necessidades e objetivos. O formato do Mapa de Empatia é o seguinte, conforme demonstra figura 2:

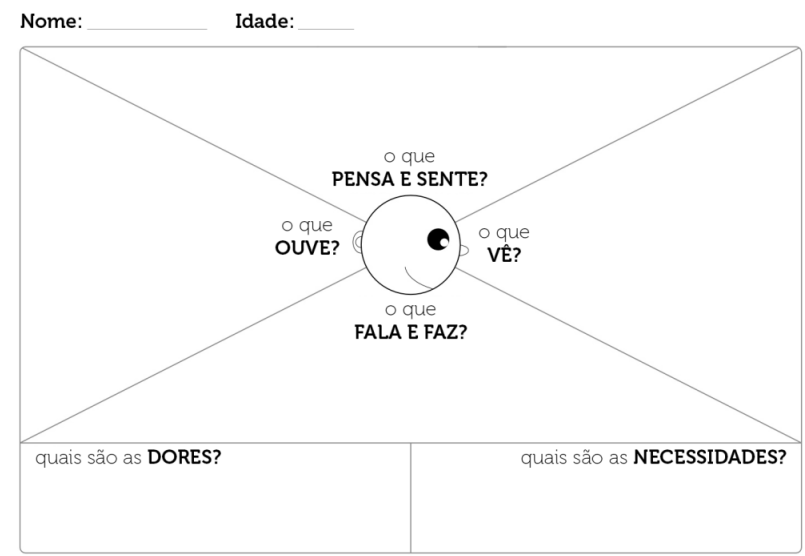

Figura 2 - Modelo utilizado do mapa da empatia(http://ramonkayo.com)

Após entrevistar um grupo de oito professores de uma instituição pública do Rio de Janeiro, com perguntas sobre o que pensam, sentem, veem, ouvem, falam, suas dores e seus ganhos, elaboramos o seguinte mapa a partir das respostas, conforme demonstra figura 3:

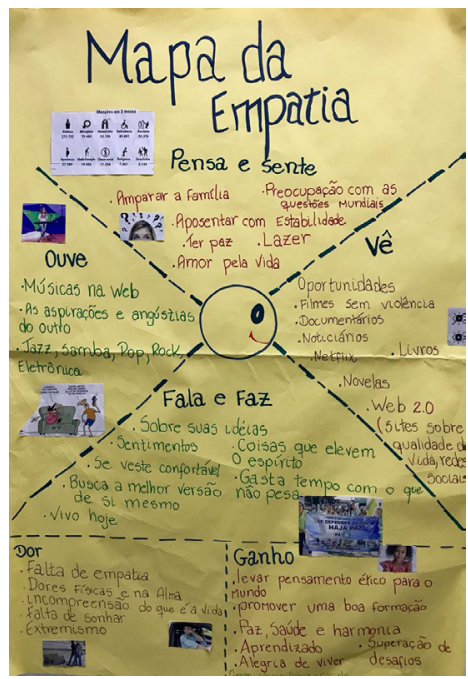

Figura 3 - Mapa da empatia (autoria própria) 
Ao analisarmos os dados tabulados no mapa, identificamos que a maior parte desse público utiliza a Web 3.0, que prefere gastar seu tempo com o que não pesa, busca paz, lazer, veem como um ganho a promoção de uma boa formação, aprendizado, alegria de viver. Sendo assim, compreendemos que a utilização da ferramenta Plickers para esse público é recomendada, pois está acostumado com as novas tecnologias, precisa de tempo para lazer e está preocupado em oferecer uma boa formação e aprendizado aos seus alunos.

A prova tradicional demanda tempo para elaboração e correção, sobrecarregando ainda mais o professor. Com a utilização da ferramenta Plickers, a correção é feita automaticamente em tempo real, e as questões ficam armazenadas em pasta para utilização em provas posteriores.

O registro dos resultados permitirá ao professor uma intervenção a cada aula para melhorar o aprendizado e proporcionar uma boa formação ao seus alunos.

\section{Preferências de leitura}

Segundo Santaella (2013), existiam quatro grandes tipos de leitores: o leitor contemplativo, leitor da idade pré-industrial, da era do livro impresso e da imagem expositiva, fixa, o leitor movente, que é filho da revolução industrial e do aparecimento dos grandes centros urbanos, é o leitor do mundo em movimento, dinâmico, das misturas de sinais e linguagens de que as metrópoles são feitas (TV, jornal, fotografias, cinema, rádio), e o leitor imersivo, que é aquele que brotou nos novos espaços das redes computadorizadas de informação e comunicação. Os três tipos de leitores coexistem, complementam-se e se completam.

O quarto tipo de leitor ubíquo nasce do cruzamento e mistura das características do leitor movente com o leitor imersivo.

Na análise do nosso público, professores de uma instituição pública do Rio de Janeiro, através do mapa da empatia, também identificamos que ele é caracterizado como este último tipo de leitor, ubíquo. Sendo assim, mediar e avaliar no ponto de vista educativo na era das tecnologias digitais, implica enfrentar o desafio de se mover com engenhosidade entre a palavra e a imagem, entre o livro e os dispositivos digitais, entre a emoção e a reflexão, entre o racional e o intuitivo. Talvez o caminho seja o da integração crítica, do equilíbrio na busca de propostas inovadoras, divertidas, motivadoras e eficazes, de acordo com Santaela (2013).

Considerando então a utilização da aplicação Plickers, importa agora descrever a ferramenta e as suas funcionalidades.

\section{O que é plickers?}

O Plickers é uma ferramenta Web 2.0, uma aplicação móvel gratuita, user-friendly, disponível na versão web e aplicativo para dispositivos móveis. Seu propósito é a administração de testes rápidos, que permite ao professor escanear as respostas e conhecer em tempo real o nível da turma quanto ao entendimento de conceitos e pontos-chaves de uma aula.

O aplicativo Plickers tem como finalidade principal favorecer uma avaliação dinâmica, que permita mensurar, instantaneamente, o nível de aprendizado. O relatório gerado ao final de cada questão possibilita uma análise acerca do aprendizado sobre cada ponto estudado, promovendo, se necessário, uma revisão direcionada ao tema que apresentou baixo rendimento.

\section{Como funciona o Plickers?}

O professor cria uma conta no site https://plickers.com/, cadastra suas turmas, cadastra suas questões, imprime os cartões (respostas) disponibilizados para impressão no site e aplica o teste de forma mais descontraída e lúdica.

Os procedimentos de cadastrar questões e turmas devem ser feitos no aplicativo na versão Web. O App para dispositivo móvel é útil somente para o professor escolher as questões e capturar as respostas através da câmera do dispositivo móvel. 
Para aplicar o teste e colher as respostas, o professor deve imprimir uma espécie de cartão para cada aluno, que é disponibilizado na plataforma ao cadastrar os alunos. Esse cartão contém um QR code, que corresponde a um código de barras bidimensional, de fácil reconhecimento por leitores de celulares equipados com câmera, que pode ser posicionado de quatro maneiras diferentes, em que cada lado está identificado por uma letra, de "a" a "d". Cada aluno, dessa forma, é representado por um cartão com um número. Assim, o professor entrega aos alunos os cartões com seus respectivos números.

Em seguida, o professor seleciona a questão e a projeta onde todos vejam, com a ajuda do computador (conectado à Internet) e do retroprojetor. Os alunos posicionam o cartão na resposta que consideram correta, conforme figura 4, e, através do App no smartphone, o professor escaneia as respostas. A ferramenta apresenta os dados do desempenho de cada aluno da turma em tempo real.

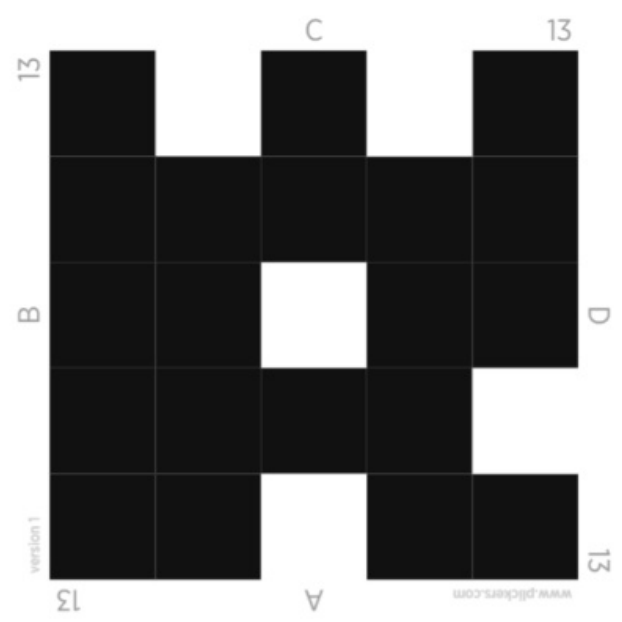

Figura 4 - Cartão resposta(https://plickers.com/)

Para responder às questões, os alunos devem escolher a posição correta, que ficará sempre no topo. Deverá levantá-lo para ser visível para o(a) professor(a), ficando os alunos a visualizar apenas o lado branco.

Os mesmos cartões podem ser utilizados em diferentes turmas, já que o professor pode escolher no seu dispositivo a turma e as questões, não existindo o risco de existir confusão com o nome dos alunos e o número do cartão associado. Por exemplo, a Maria, na turma A, terá sempre associado ao seu nome o cartão 5; contudo, o mesmo cartão será associado ao João, na turma B, sem existir qualquer conflito.

Durante a atividade, são projetadas na tela as informações sobre a identificação dos alunos que estão respondendo, dos que faltam responder e ainda se resposta está correta ou não. O feedback e correção são, deste modo, instantâneos.

As respostas dos alunos ficam armazenadas de forma digital na plataforma online https://plickers.com/. Os dados podem ser visualizados por data, por resposta, por atividade e por aluno.

A ferramenta permite a aplicação de diversos tipos de exercícios com questões de múltipla escolha, verdadeiro ou falso, completar lacunas e atividades de promoção do espírito crítico, sondagens, introdução de novos tópicos ou Warm-ups (aquecimento de uma aula) e questionários de autoavaliação.

Permite também a utilização de texto e imagens, o que pode ser muito útil para diversificar os tipos de exercícios, como, por exemplo, utilização de imagens para discussão de conceitos abstratos. 
A figura 5 demonstra a utilização da ferramenta:
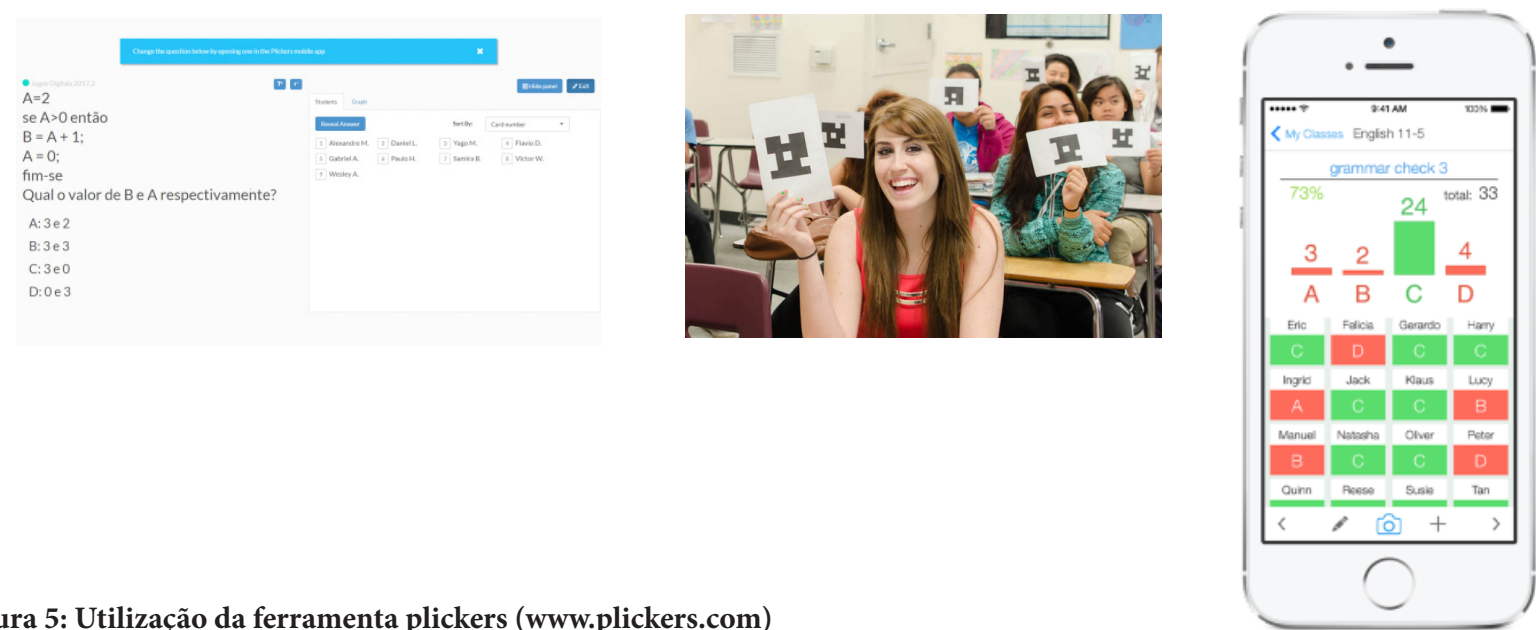

Figura 5: Utilização da ferramenta plickers (www.plickers.com)

Com base nas análises feitas, os autores desse artigo propõem a ressignificação da prova escrita, substituindo-a pela utilização contínua da ferramenta plickers, pois, além de melhorar a linguagem e a condição de fruição, alinha-se às novas tecnologias, aproximando-se da realidade do leitor ubíquo, definido por Santaela (2013), e promovendo uma avaliação formativa.

\section{Relato da experiência com a ferramenta Plickers}

O professor relata que as normas da instituição sobre a avaliação do curso ministrado por ele deve ser feita da seguinte forma:

O aluno será avaliado através dos seguintes instrumentos e seus respectivos valores:

- $\quad$ Prova teórica: 4,0 pontos .

- Prova prática: 6,0 pontos.

- Índice para Aprovação: Nota final 6,0 e frequência mínima de 75\%.

Após conhecer a ferramenta Plickers em uma Oficina de Ferramentas Digitais para Educação, no Seminário Professores para o Futuro realizado pelo IFRJ, o professor resolveu realizar a prova teórica escrita para avaliar seus alunos, a qual será objeto de ressignificação com a ferramenta Plickers.

O professor relata que, durante a aplicação da prova teórica no modelo tradicional em turmas de outros cursos que ministrou, os alunos mostravam-se tensos, alguns desistiam do curso quando descobriam que iriam ser submetido a tal prova e outros desistiam após a aplicação, quando recebiam o resultado, causando assim uma evasão significativa do curso por medo do fracasso.

Ao passar a utilizar a ferramenta Plickers para avaliar a apreensão dos assuntos abordados em cada aula, o professor relata que os alunos mostraram-se mais descontraídos, pois, além da dinâmica lúdica da avaliação, eles tiveram um feedback imediato dos assuntos que por ventura não foram bem assimilados. Dessa forma, todos ganharam: alunos tiveram a oporturtunidade de rever tais conteúdos e o professor pôde reforçá-los nas aulas seguintes, visto que ele passou a ter um registro da avaliação de cada questão da prova, passando dessa forma a ter um caráter formativo em vez de classificatório. 
A ferramenta permite também que o professor aplique uma autoavaliação com os alunos, permitindo a eles uma reflexão e debate sobre o processo de aprendizagem. A partir daí, a avaliação prática passou a ser baseada na construção de um artefato (jogo digital) durante cada aula do curso. A cada assunto abordado, os alunos foram incrementando o seu artefato, permitindo, assim, um ambiente de criação e circulação de novas ideias. É possível afirmar que, como consequência, a evasão diminuiu significativamente e aprendizagem melhorou consideravelmente.

O professor relata que otimizou seu tempo com formulações e correção de provas, pois o aplicativo armazena todas as questões em pastas divididas por assunto e corrige automaticamente as questões em tempo real gerando relatórios que armazenam os resultados.

A ferramenta permitiu economizar papel com a impressão das provas, pois os cartões-resposta, uma vez impressos, podem ser reutilizados centenas de vezes em outras avaliações e turmas, contribuindo para sustentabilidade do planeta.

O professor passou a ter mais tempo livre para outras atividades, visto que não precisou levar provas para corrigir em casa.

O único ponto que o professor relatou que precisaria ser melhorado seria a possibilidade de incluir questões dissertativas, uma vez que a ferramenta só permite questões objetivas.

Ao aplicar um questionário de avaliação do processo, através da ferramenta, os alunos relataram que as avaliações de todos cursos poderiam ocorrer dessa forma. Foram obtidos os seguintes resultados: $75 \%$ dos alunos preferiram a realização da prova com a ferramenta Plickers; $100 \%$ concordaram que a ferramenta propicia uma maior descontração em relação à prova tradicional; $50 \%$ relataram que a experiência com a ferramenta foi excelente, $25 \%$ boa e $25 \%$ regular.

O professor compartilhou sua experiência com outros professores da instituição e com a direção da escola, que solicitou que o docente promova uma oficina da ferramenta, para que outros professores possam também utilizá-la.

\section{Considerações finais}

$\mathrm{Na}$ avaliação da aprendizagem, o professor não deve permitir que os resultados das provas periódicas, geralmente de caráter classificatório, sejam supervalorizados em detrimento de suas observações durante o processo de aprendizagem. Entretanto é humanamente impossível para o professor, que geralmente necessita trabalhar em diversas escolas com um grande número de alunos, registrar a evolução de cada um deles.

Uma contribuição para mudar este cenário pode ser encontrada com a ferramenta Plickers que permite uma avaliação do processo de ensino aprendizagem, conforme demonstrado no relato do professor.

Contudo, não basta uma apropriação da tecnologia; é preciso adequar a metodologia de uso para propiciar uma avaliação mais justa, pois se o professor puramente substituir a prova escrita pela sua transcrição na ferramenta continuará promovendo uma avaliação classificatória.

A ferramenta deve ser utilizada continuamente ao longo do processo de ensino/aprendizagem para que o professor possa intervir e propiciar ao aluno momentos de reflexão sobre sua aprendizagem, pois sem um feedback imediato o aluno que não sabe exatamente como estudar ou que está inseguro com o conteúdo que está aprendendo pode ficar relutante em seguir se dedicando às suas tarefas.

Esperamos, com este artigo, contribuir para a divulgação da ferramenta móvel Plickers e motivar outros professores para a sua utilização e para outros estudos com outras ferramentas.

Dentre as limitações deste experimento, destacamos a necessidade de uma maior formalização na sua realização, incluindo a coleta de dados mais organizada e extensa, além da impossibilidade de aplicar questões discursivas com a ferramenta.

Como trabalhos futuros, sugerimos a repetição do experimento em outras disciplinas e cursos, para avaliar a receptividade de alunos com diferentes perfis. 


\section{Referências Bibliográficas}

BENTO, Maria Cristina Marcelino. Metodologias Ativas E Novas Tecnologias: O Uso Do Plickers Como Ferramenta De Avaliação, CENTRO UNIVERSITÁRIO TERESA D’ÁVILA, 2017.

CARDOSO, Rafael. Design Para um Mundo Complexo, Cosac Naify, 2012.

COELHO, Luiz Antonio L. A reflexão pelo conceito. Anais do Congresso Internacional do Design da Informação, 2003.

CUNHA, Gabriela. Plickers: uma ferramenta feita para professores que amam ensinar sem enrolar. Disponível em <http://aulaincrivel.com/plickers/> Acesso em 05 de dezembro de 2017.

HORN, R. Visual language: global communication for the 21 the century. Washington: Macrovu Inc, 1998.

KRAEMER, Maria Elisabeth Pereira. A avaliação a aprendizagem como processo construtivo de um novo fazer, UFSC, 2005.

LIBÂNEO, José Carlos. Didática. São Paulo: Cortez, 1994.

LUCIANO, Hélio José. MORAES, Dirce Aparecida Foletto de. Prova Escolar: Da Classificação Ao Medo, Universidade Estadual de Londrina, 2013.

LUCIANO, Hélio José. MORAES, Dirce Aparecida Foletto de. Representações Docentes Sobre Prova Escolar: Em Busca De Uma Ressignificação, Universidade Estadual de Londrina,2013.

LUCKESI, CIPRIANO C. Avaliação da Aprendizagem escolar: estudos e proposições. 19 ed. São Paulo: Cortez, 2008.MARTINS, Bianca. COUTO, Rita. Aprendizagem Baseada em Design: uma pedagogia que fortalece os paradigmas da educação contemporânea, Anais [Oral] do $7^{\circ}$ Congresso Internacional de Design da Informação, 2015.

MENDONÇA, Telma JoãoVasconcelos. A utilização da aplicação móvel Plickers no processo de ensino e aprendizagem da língua inglesa no Ensino Secundário, Universidade de Lisboa, 2017.

MORAES, Dirce Aparecida Foletto de. Avaliação formativa: re-significando a prova no cotidiano escolar. Universidade Estadual de Londrina, Londrina, 2008.

PERRENOUD, Phillipe. Avaliação: da excelência à regularização das aprendizagens: entre duas lógicas. Porto Alegre, Artmed, 1999.

SANTAELLA, Lucia. Leitor prossumidor: Desafios da ubiquidade para a educação, PUC-SP, 2013.

SCHLEICHER, A. Schools for 21st-Century Learners: Strong Leaders, Confident Teachers, Innovative Approaches. Paris: OECD Publishing, 2015.

Site Plickers. Disponível em <https://plickers.com/> Acesso em 05 de dezembro de 2017.

SOUZA, Jane Aparecida Gonçalves. Práticas avaliativas: reflexões, UFJF, 2010.

VIANNA, Maurício. VIANNA, Ysmar. ADLER, Isabel. LUCENA ,Brenda. RUSSO, Beatriz. Design Thinking - Inovação em Negócios. 1a ediçao, MJV Press, 2012.

\section{Contato dos autores}

Marcelo Queres de Oliveira | mqueres@gmail.com Adriano Barbosa Lima | barbosalimas@gmail.com Heloisa Elaine da S. C. Lopes | heloisaelainelopes@gmail.com

Bianca Martins | bmartins@unicarioca.edu.br

Verônica Elói | valmeida@unicarioca.edu.br

Victor Gonçalves Freitas | vfreitas@unicarioca.edu.br 